\title{
TRENDS OF CURRENT DYNAMICS OF CHEMICAL PROCESSES IN THE SOILS OF ODESSA REGION
}

\author{
Bilanchyn Yaroslav ${ }^{a}$, Rezvaya Svetlana ${ }^{a *}$, Medinets Sergiy $^{\mathrm{a}}$, Pitsyk Vasiliy ${ }^{\mathrm{a}}$ \\ ${ }^{a}$ Odessa National I. I. Mechnikov University, 2 Dvorianskaya str., Odessa, 65082, Ukraine \\ *e-mail: grunt.onu@mail.ru
}

\begin{abstract}
Results of chemical processes' dynamic studies of many years (1971-2011) in the soils of Odessa Region have been described. The most significant in the last 15-20 years have been changes of humus content and ecological $\&$ agrochemical status of black soils. In spite of some increase in the norm of fertilizers input for the last 5 years the negative balance of plant nutrition elements in soils is preserved. Ways of optimization of humus and ecological \& agrochemical status of soils in the region and increase of their fertility have been proposed.
\end{abstract}

Keywords: Odessa Region, black soils, humus content, ecological \& agrochemical status.

\section{Introduction}

Exchange of matter and energy between soil and other natural bodies (soil, water, atmosphere, living matter), inflow of radiant energy, life activity of soil living phase are the most important factors and reasons of transformation and displacement of substances and energy in soil. It combination they form the reason for emergence of different in their nature, direction and essence interconnected and mutually caused soil processes.

Different phenomena of physical, chemical, physicochemical and biological nature are taking place in soil permanently. Their joint influence ensures development and functioning of soil as non-living material of nature and the main means of economic development and use. According to their character the processes in the soil could be divided into three groups [1]: processes of exchange of matter and energy between soil and other natural bodies (processes of inflow into the soil and removal from soil); processes of matter and energy transformation in soil; processes of moving of matter and energy in soil body.

In soil cover of Odessa Region (Ukraine) over $90 \%$ of area are black soils. In the north of the Oblast, in the foreststeppe part of its territory these black soils are typical and regraded, in the steppe central and southern part of the Oblast territory - black soils common and southern. In the Dnister Region the black soils are southern and common micellar and carbonate. The level of plowing up the area is quite high in the Oblast - around $80 \%$ of agricultural lands. The irrigated area in the Oblast (mainly black soils southern) is 226,9 thousand Ha. The waters used for irrigation are fresh water $\left(0,4-0,6 \mathrm{~g} / \mathrm{dm}^{3}\right)$ of the Danube and Dnister Rivers, as well as water of lower quality and higher mineralization (1-2 $\mathrm{g} / \mathrm{dm}^{3}$ and more) from the Lower Danube Lakes-reservoirs.

The main chemical, physical and biochemical processes in the black soils of the Oblast, which are forming their composition, regimes, properties and determining fertility level - dissolution-migration-accumulation, exchange and consumption of matters and elements; various reactions of decomposition of organic substances in the plant litter; similarly diverse phenomena of microbial decomposition and synthesis, formation and degradation of organo-mineral compounds, humus included; mineralization of humus substances; gas-atmospheric fixation and emission including the processes of ammonification, nitrification and denitrification; two-sided exchange of ashes, elements and nitrogen in the system soil-higher vegetation and many others.

Since 1990 the direction and intensity of chemical processes in the Region changed both in the zonal non-irrigated and in irrigated soils, which entail gradual changing of their composition and properties, most often soil degradation. The most vivid is degradation of humus content and ecological \& agrochemical state of the black soils dominating in the Region, as the result of which in the last 15-20 years evident trend towards decrease in their fertility has been observed [2,3]. In connection with the above, this paper focuses on the results of studies of modern dynamics of the main parameters of humus and ecological \& agricultural state of black soils in the Region, both under the background rain-fed (boharic) conditions and in the irrigated areas.

The objective of the paper is to reveal trends in modern dynamics of chemical processes in the soils of the Region and substantiate the ways of optimization of the main parameters of their composition and properties, first of all of their humus content and ecological \& agrochemical state.

\section{Organization and Performance of Work and Researches}

Studies of chemical processes' dynamics in the soils of Odessa Region have been carried out for many years (19712011) in the key stationary plots of soils and lands state monitoring, both under the background non-irrigated land use and 
on the irrigated areas in the steppe part of the Region [2]. In accordance with programme and methodology of monitoring we determine periodically the parameters and characteristics of soil morphology and tendencies of their changes, general physical and water-physical properties, $\mathrm{pH}$, grain size, soil structure and micro-structure, humus content and humus store, content of total NPK and accessible for plants NPK. In the framework of the NitroEurope International Project processes of nitrification and mineralization of organic nitrogen, as well as nitrification capacity of the black soils had been studied since 2007 in the area of "Petrodolinskoye" monitoring station with background southern black soils [4]. For all the key plots (stations) of monitoring source values (characteristics) of soil parameters controlled had been borrowed from the materials of large-scale survey of soils of the Region (1958-1961) and subsequent correction of those materials in 70$80^{\text {th }}$. Apart from our own results of study of chemical processes in soils of the Region we also used materials of soil and soil-amelioration surveys of lands carried out in the last 30-40 years by Odessa Branch of the "Ukrzemproekt" Institute, Odessa Hydro-Geological \& Amelioration Expedition and Odessa Research \& Production Centre "Oblderzhrodyuchist".

Most of these materials are given in the paper quoted here [2].

\section{Main Results of Studies and their Discussion}

The most important in the soil forming of the Region, and black soils forming in particular, are the processes of sod pedogenesis and calcium hydrocarbonate migration in profile. These two processes are forming two main profiles of black soils - humus and carbonate ones, as well as the main parameters and characteristics of their material \& chemical composition and properties. As the result of sod process much humate- and calcium humus accumulate in profile being closely connected with mineral part, as well as much biophil elements - nitrogen, phosphorus, sulfur, calcium, iron, manganese and other macro- and micro-elements. At that structuring of soil mass is taking place, with forming of waterresistant crumb structure. The last is the result of influence of thin grassy roots, activities of invertebrates, waste products of microorganisms and adhesive characteristics of humus substances. Due to their structure the black soils, especially those typical for the north of the Region, have good physical and water-physical properties and the upper humus horizon is loose and have optimal porosity, density, permeability and water capacity.

Migration and accumulation of carbonates in the profile of black soils provide for high level of saturation of their colloids with calcium and absence on the most part of the Region's area of eluvial - illuvial differentiation of profile of silt (grain under $0,001 \mathrm{~mm}$ ), iron and aluminum. Humate - calcium composition of humus, as well as neutral and weakly alkaline reaction of soils are formed. This means that migration of calcium hydrocarbonate and presence of horizon of carbonate accumulations in the profile contribute to stability of soil mass of black soil, its properties, and in significant measure to potentially high fertility.

We would like to present some analytical characteristics of the processes of formation and values of the main parameters of material \& chemical composition and properties of black soils in the Region as of the beginning of our studies. In the typical black soils and regarded black soils in the north of the Region humus content in the upper horizons makes $4,5(4,7)-6,0(6,5) \%$. With the depth of profile its quantity decreases gradually, and in the depth of 50-60 cm makes $3,0-3,5 \%$. Capacity of cationic uptake is $40-50 \mathrm{mmol} / 100 \mathrm{~g}$ of soil, share of exchangeable calcium is in average $80 \%$ of capacity. Environmental reaction is neutral or close to neutral. Plant nutrition elements' content is: nitrogen - on the level of $70 \mathrm{mg} / \mathrm{kg}$, phosphorus $60-90$ and potassium $100-120 \mathrm{mg} / \mathrm{kg}$. In the common black soils of steppe zone that are dominating in the territory of the Region humus content in the upper horizons is $4,4-4,6$ to $5,5-6,0 \%$ to the east of the Dnister valley and $3,0-4,0(4,5) \%$ in the micellar - carbonate warm facie of the areas to the west of the Dnister. At the depth of 50-60 cm humus content is 2,9-3,4 and 1,8-2,4\% accordingly. Significantly lower quantity of humus in the black soils of warm facie is explained by their high bioactivity and strengthening of the processes of plant residues mineralization. Capacity of cationic uptake in the common black soils in most cases is $40-45 \mathrm{mmol} / 100 \mathrm{~g}$, share of calcium makes 80$85 \%$ of capacity. Environmental reaction is neutral and weakly alkaline. These soils are medium and well provided with plants nutrition elements: nitrogen - 70-90 (up to 100) $\mathrm{mg} / \mathrm{kg}, \mathrm{P}_{2} \mathrm{O}_{5} 80-110$ and $\mathrm{K}_{2} \mathrm{O}-100-120$ (up to $140-160$ ) $\mathrm{mg} / \mathrm{kg}$. And, finally, in the most xeromorphic southern black soils in the south of Region humus content in the upper horizons makes usually 3,5-3,9\% to the east of the Dnister and 2,7 (2,9) - 3,1 $(3,3) \%$ to the west of the Dnister. At the depth of $50-60 \mathrm{~cm}$ its quantity goes down quite sharply to $1,3-1,5 \%$. Capacity of cationic uptake is $32-38 \mathrm{mmol} / 100 \mathrm{~g}$. Share of consumed magnesium and sodium increases here, especially in the coastal zone to the east of Odessa, which evidences residual and sometimes current alkalinity of southern black soils in the Region. Reaction of soils is weakly alkaline and alkaline (usually $\mathrm{pH}$ is 7,5-7,8). Content of nutrients goes here down if compared with black soils of middle and northern parts of the Region which are better watered [2,5].

Under conditions of agricultural development of black soils the sod process becomes significantly weaker due to decrease of mass of roots and invertebrate fauna. Under extensive system of land-use dominating in the Region the process of humus accumulation slows down compared to its mineralization and the processes of damaging of structure with agricultural machinery prevail over the structure-formation processes. Under these conditions black soils slowly become poor in humus (dehumification), their valuable for agronomy crumby structure eventually diffuses. These 
processes especially intensified in the last 20 years because of extensification of land use and decrease of the norms of input of organic and mineral fertilizers, as well as ameliorants. Thus, the quantity of organic fertilizers applied in the Region in 2001-2005 was 17,7 times less if compared to 1986-1990.

Irrigation of black soils in the south of the Region practically always cause increase in them of mobility of carbonates and humus substances, decrease of capacity of cationic exchange and content of adsorbed calcium. Shares of adsorbed magnesium and sodium increase, which evidences the processes of alkalinization and salinization of black soils with irrigation. At that the parameters of their agro-physical state worsen as the result of aggregates destroying - slitization and crust forming, increase of density and hardness, decrease of permeability, increase of hydrophilic properties of irrigated fields. More intensive degradation in the source non-carbonate black soils irrigated with low quality waters having high mineralization (1-3, sometimes $\left.4-5 \mathrm{~g} / \mathrm{dm}^{3}\right)$ containing sodium and magnesium. And significantly less changes take place with irrigated black soils in case of their carbonateness, no-deficit humus and calcium balance, careful regime of irrigation with water of respective quality, as well as keeping to respective culture of irrigated agriculture [2,3].

As it was shown by results of many years' studies of dynamics of modern processes in the soils of the Region, the most significant changes took place with humus and ecological \& agrochemical state of black soils in the last 15-20 years. In particular, comparison of results of agrochemical survey of soils of the Region in 1986-1990 and in 2001-2005 shows the tendency towards dehumification of soils, especially black soils. While in 1986-1990 in the arable horizons of the soils surveyed humus content made 3,76\%, in 2001-2005 it decreased to 3,20\%. This means that humus content in the soils of the Region for the 15 years being analyzed had decreased in average $0,56 \%$ or $14,9 \%$ of the humus content in $1986-1990$. In the Region in average loss of humus for those 15 years made 17,50 t/Ha or 1,17 t/Ha annually (for comparison - in the period of intensification of agriculture in 1960-1980 losses of humus were on the level of $0,5-0,7 \mathrm{t} / \mathrm{Ha}$ a year). The most significant dehumification losses took place in the initially better humused typical and regraded black soils in the north of the Region - decrease in humus content made here $0,79 \%$ of weight and $17,9 \%$ compared to source quantity, $24,69 \mathrm{t} / \mathrm{Ha}$ for 15 years and 1,65 t/Ha in average for a year. In less humused common black soils of steppe zone values of humus losses for 15 years somewhat decreased if compared to black soils of northern forest-steppe part of the Region - respectively 0,50 and 14,0\%, 15,63 and 1,04 t/Ha. The lowest losses in humus for the period analyzed were suffered by southern micellar-carbonate black soils in the areas to the west from the Dnister. As it was pointed out above, those are relatively most xeromorphic and initially less humused $(3,0 \pm 0,3 \%)$ black soils in Odessa Region. Loss of humus for the analyzed 15 years here made 0,28 and $9,0 \%, 8,75$ and $0,58 \mathrm{t} / \mathrm{Ha}$ respectively.

Results of many years' monitoring of soils state in the Region also show the tendencies to eventual decrease in the last 15-20 of black soils' provision with plants nutrition elements. Despite somewhat increase of the norm of fertilizers application in the last 5 years and visible decrease of intensity of black soils dehumification processes, they still have negative balance of plants nutrition elements (NPK).

Based on the results of many years study of dynamics of chemical processes in the soils of Odessa Region a system of measures has been substantiated to improve black soils' state and rise their fertility. Those are measures to protect soils from water and wind erosion, introduction of scientifically grounded crop rotation with soil-amendment crops. Very important is to increase the norms of fertilizers application, both mineral (first of all nitrogen and phosphorus) and organic. Without organic fertilizers it would be impossible to overcome modern tendency towards decrease of black soils' humus content, worsening of parameters of their agro-physical and ecological \& agrochemical state and biochemical regime. In the irrigated massive it is also recommended to apply calcium-containing ameliorants and deep tillage from time to time.

\section{Conclusions}

1. Results of chemical processes' dynamic studies of many years (1971-2011) in the soils of Odessa Region forming morphology of their profile, material \& chemical composition, regimes and properties determining fertility level have been described and discussed. The main volume of studies has been done on the dominating in the Region (over $90 \%$ of area) black soils - regraded, typical, common and southern, both non-irrigated and irrigated.

2. It has been established that in the past 20 years on the background of tendency towards agriculture extensification the direction and intensity of chemical processes in the soils of Odessa Region have changed, which entails changes in their composition and properties, most often degradation. Degradation changes in humus content and ecological \& agrochemical state of black soils are the most notable, as the result in the last 15-20 years evident tendency towards fertility decrease is observed.

3. System of measures has been substantiated to improve black soils' state and to rise their fertility. The system comprises in particular a complex of measures to protect soils from erosion, introduction of scientifically grounded crop rotations with soil-amendment crops, application of recommended norms of mineral and organic fertilizers. Especially effective is application of organic fertilizers which would enable us to stop development of current processes of black soils' dehumidification, worsening of their agro-physical and ecological \& agrochemical state and characteristics of biochemical regime. 


\section{References:}

[1]. Rode A.A. System of research methods in soil science; Nauka, Siberia Branch: Novosibirsk, 1971, 93p. (In Russian)

[2]. Gogolev I.N.; Baer R.A. et al. Irrigation in Odessa Region. Soil-Ecological and Agrotechnical Aspects; Gogolev I.N.; Druzyak V.G. (editors); Editorial Dept. Of State Regional Administration: Odessa, 1992, 436p. (In Russian)

[3]. Bilanchyn Ya.M. Irrigation and Black Soils of Irrigated Massive in South Ukraine and Odessa Region at the Boundary of Third Millennium; In: Bulletin of Odessa National University. Geographic and Geological Sciences, Volume 16, Edition1, 2011, p.123-132 (In Ukrainian)

[4]. Medinets S. V., Pitsyk V. Z., Bilanchyn Ya. M., Medinets V. I., Skiba U., Kotogura S. S., Goshurenko L. M. Study of Nitrification and Mineralization of Nitrogen in Southern Chernozem Black Soils in Lower Dnister Region. In: VII international academic and research conf. proceedings of "Ecological and economical problems of Dnister River”, (Odessa, 7-8 ${ }^{\text {th }}$ October 2010) / Od: Invatz, 2010. - p. 49 (in Russian).

[5]. Valda O.K., Krakovskiy M.I. Soils of Odessa Region; Odessa Land-Planning Agency: Odessa, 1969 , 52 p. (In Ukrainian). 